\title{
Proceeding
}

Supplementary Issue: Summer Conferences of Sports Science. Costa Blanca Sports Science Events, 25-26 September 2020. Alicante, Spain.

\section{Finding tennis talents in Greece}

\author{
IOANNIS ATHANAILIDIS
}

School of Physical Education and Sports, Democritus University of Thrace, Komotini, Greece

\begin{abstract}
The aim of the present study is to investigate motor skills in children ages 6-11 in Greece with the focus on tennis. Motor abilities in tennis is the main condition for future high performance. A series of tests of AST (Allgemeiner Sportmotorischer Test 1990) were used for the purposes of the present study. Participants included 124 primary school students. These tests included six tasks: running (20 meters, hurdles and 6' running) and throwing (tennis ball throwing to a target, ball throwing on the wall and medicine ball throwing). Results did not show significant differences between boys and girls. Differences found between boys and girls focused mainly on motor coordination and ball handling. The explanation for such differences is based on the fact that boys are more used to play with balls in relation to girls.
\end{abstract}

Keywords: Test; Tennis; Talent; Greece.

\section{Cite this article as:}

Athanailidis, I. (2020). Finding tennis talents in Greece. Journal of Human Sport and Exercise, 15(4proc), S1030-S1034. doi:https://doi.org/10.14198/ihse.2020.15.Proc4.05

Corresponding author. School of Physical Education and Sports, Democritus University of Thrace, Komotini, Greece.

E-mail: iathanai@phyed.duth.gr

Abstract submitted to: Spring Conferences of Sports Science. Costa Blanca Sports Science Events, 19-20 June 2020. Alicante, Spain.

JOURNAL OF HUMAN SPORT \& EXERCISE ISSN 1988-5202

(c) Faculty of Education. University of Alicante

doi:10.14198/jhse.2020.15.Proc4.05 


\section{INTRODUCTION}

The basic criteria for the selection of children in tennis are those characteristics related to anatomy (height, weight) as well as motor skills of children in primary school.

Motor skills are the individual characteristics that are included in the genetic code and are characterized by endurance and stability. They play and important role in the development and performance of motor skills (the individual ability to reach a result with the best possible efficiency). Motor skills are divided to gross and fine motor skills. Gross motor skills are related to muscle and circulatory system while fine motor skills relate to the level of assembling and coordinating movement and depend on learning processes and adjustments based on the higher brain centres of the central nervous system Doloma (2019).

The development of fine motor skills is not an independent process from this of learning motor skills. On the contrary, their level determines the rhythm and way of accessing new motor skills as well as the efficiency level of their use (Kambas 2003).Many scientists report a different number of basic fine motor skills for children ages 5-11.Hirtz (1985), referring to primary school children, included the following in his list:

- The complex skill of reaction.

- Rhythmic ability.

- Balance.

- The ability of kinaesthetic variation.

- Orientation.

Blume (1981) added the ability to combine motors and adaptability. Starosta (1995) included motor coordination and the expression of feelings. In 1998 he also included movement harmony keeping always considering whether all the above-mentioned fine motor skills are basic or not. According to other studies the most important differences were found between kindergarten and $11^{\text {st }}$ grade students. In their study, Barnett van Beurden, et al (2008), supported that the development of motor skills during childhood is vital for a healthy life, considering that it will allow children to successfully participate in various leisure and/or sports activities (individual or team) throughout their lives. In general, the level of development of skills determines the differences between individuals on learning and performance (Gallahue \& Ozmun, 1995).Abilities are relatively continuous characteristics that are mostly genetically determined, vary according to exercise or experience and affect the performance of motor skills (Schmidt\& Lee, 1999). Cognitive skills relate to memory processes, perception skills relate to problem solution and the speed of information processing (Magill, 1998).

\section{METHODOLOGY}

The AST(Allgemeiner Sportmotoricher Test, 1990) was used:20meters sprint, throwing of tennis ball to target, ball throwing to the wall and under the feet, turning and catching the ball, hurdles, medicine ball throwing, 6 minutes running around a volleyball court. Participants included 124 children ( 61 boys and 61 girls) in primary school, ages 6-11. Each age was separately assessed. For running tests $(20$ meters, hurdles, 6 minute running) participants had two tries and the best one was assessed. The same procedure was followed for the throwing tests. 
Table 1. Exercise included by the test and the pursued target.

\begin{tabular}{|c|c|}
\hline Exercises & Pursued ability \\
\hline 20 Meters sprint & Speed-anaerobic non -lactic \\
\hline Ball throwing with target & Coordination abilities with precision exercise (partial Precision) \\
\hline Ball-feet-wall & Skilful with ball, total body coordination ability in exercise with precision \\
\hline Exercise with hurdles & $\begin{array}{l}\text { Quickness, skilfulness, total coordination in complex exercise under time } \\
\text { pressure }\end{array}$ \\
\hline Throwing medicine ball & Quick- strength in hands and thoracic muscles \\
\hline 6 Minutes running & General aerobic strength \\
\hline
\end{tabular}

\section{Procedure of test}

1. Two efforts, the best is valid.

2. Three squares, small square 3 points, medium square 2 points, big square 1 point.

3. There are two rows with five efforts and at the end we have the addition of all points.

4. Two efforts with best score (time).

5. Throwing the medicine ball ( $11 \mathrm{~kg}$.) two efforts.

6. 6 minutes strength, in volleyball court/ one round is 54 meters.

\section{RESULTS}

Variation Analysis MANOVA was used. Age and gender means are shown in Table 2. Interactions of genderage are shown, in Table 3. Frequencies show that $67,3 \%$ of the children do sports, $22,4 \%$ are members of a club and $23,4 \%$ of the children have parents that are members of clubs. Finally, the correlation between tests is shown in Table 4. There were two groups in running tests (20 meters, hurdles, 6' running) and throwing tests (ball throwing to target, ball throwing to wall and medicine ball throwing). Running tests show an intercorrelation (anaerobic alactic, aerobic ability) and throwing tests (coordinating ability and power).

Table 2. Means by age and gender.

\begin{tabular}{llll}
\hline Age & 20 M Sprint & Ball throwing with target & Ball-Feet-Wall \\
\hline 6 & 4.9900 & 9.6667 & 4.0000 \\
7 & 4.6135 & 8.8000 & 5.0500 \\
8 & 4.5053 & 8.8667 & 5.3125 \\
9 & 4.4314 & 11.7273 & 8.9048 \\
10 & 4.0670 & 12.6957 & 11.6250 \\
11 & 4.0739 & 14.4211 & 22.5789 \\
\hline Gender & & & \\
\hline Boy & 4.3086 & 12.2745 & 12.2500 \\
Girl & 4.4111 & 10.3571 & 9.2778 \\
\hline Age & Exercise with hurdles & Throwing medicine ball & 6 min running \\
\hline 6 & 27.5350 & 2.3000 & 756.0000 \\
7 & 25.7844 & 3.1940 & 647.8148 \\
8 & 23.9350 & 3.5281 & 737.3333 \\
9 & 22.0209 & 4.3714 & 847.1739 \\
10 & 22.8148 & 5.3152 & 936.9048 \\
\hline S1032 & $2020 \mid$ Proc4 | VOLUME 15 & & ○ 2020 University of Alicante
\end{tabular}




\begin{tabular}{llll}
11 & 23.0300 & 5.5316 & 857.1579 \\
\hline Gender & & & \\
\hline Boy & 22.4538 & 4.4071 & 776.5882 \\
Girl & 24.6210 & 4.2825 & 818.5789 \\
\hline
\end{tabular}

Table 3. Gender and age interaction in all tests as shown by the multiple variation analysis (MANOVA).

\begin{tabular}{lllllll}
\hline $\begin{array}{l}\text { Interactive } \\
\text { age-gender }\end{array}$ & $\begin{array}{l}20 \mathrm{~m} \\
\text { sprint }\end{array}$ & $\begin{array}{l}\text { Ball throwing } \\
\text { with target }\end{array}$ & $\begin{array}{l}\text { Ball-feet- } \\
\text { wall }\end{array}$ & $\begin{array}{l}\text { Exercise } \\
\text { with hurdles }\end{array}$ & $\begin{array}{l}\text { Throwing } \\
\text { medicine ball }\end{array}$ & $\begin{array}{l}6 \text { min } \\
\text { running }\end{array}$ \\
\cline { 2 - 7 } & $p=.539$ & $p=.075$ & $p=.033$ & $p=.071$ & $p=.972$ & $p=.000$ \\
\hline
\end{tabular}

Table 4. Correlations between tests.

\begin{tabular}{lccc}
\hline & 20 $\mathrm{m}$ sprint & Ball throwing with target & Ball-feet-wall \\
\hline \multirow{2}{*}{$20 \mathrm{~m}$ sprint } & 1.0000 & -.3945 & -.5237 \\
Ball throwing with target & -.3945 & $p=.000$ & $p=.000$ \\
& $p=.000$ & 1.000 & .4846 \\
Ball-feet-wall & -.5237 & & $\mathrm{p}=.000$ \\
& $p=.000$ & .4846 & 1.0000 \\
Exercise with hurdles & .4751 & $p=.000$ & -.3676 \\
& $p=.000$ & -.2811 & $p=.000$ \\
Throwing medicine ball & -.5187 & $p=.008$ & .6084 \\
& $p=.000$ & .4374 & $p=.000$ \\
6 min running & -.3257 & $p=.000$ & .2821 \\
& $p=.002$ & .3696 & $p=.008$ \\
\hline \multirow{2}{*}{$20 \mathrm{~m}$ sprint } & Exercise with hurdles & Throwing medicine ball & 6 min running \\
Ball throwing with target & .4751 & -.5187 & -.3257 \\
& $p=.000$ & $p=.000$ & $p=.002$ \\
Ball-feet-wall & -.2811 & .4374 & .3696 \\
Exercise with hurdles & $p=.008$ & $p=.000$ & $p=.000$ \\
Throwing medicine ball & -.3676 & .6084 & .2821 \\
& $p=.000$ & $p=.000$ & $p=.008$ \\
6 min running & 1.0000 & -.2728 & -.3485 \\
& -.2728 & $p=.011$ & $p=.001$ \\
& $p=.011$ & 1.0000 & .3627 \\
& -.3485 & .3627 & $p=.001$ \\
& $p=.001$ & $p=.001$ & 1.0000 \\
\hline
\end{tabular}

\section{DISCUSSION AND CONCLUSIONS}

Results did not show significant differences between boys and girls regarding their age. In order to better understand the results tests were divided in running (20 meters, 6 ' running, hurdles) and throwing (ball throwing to target, ball throwing with catching and medicine ball throwing). Regarding running tests, no significant differences were found regarding age and gender. Significant differences related to age and gender were found in throwing tests (power, coordination ability and accuracy and accuracy with the ball). Boys showed better performance on ball related tests since they were used to play with a ball from a very 
young age. In conclusion and especially in tennis since it is a rather mental game (focus, observation and accuracy), there is a need for training on fine tasks with the use of a ball. According to Causgrove - Dunn and Watkinson (1996), it is possible that some of the skills in assessment processes, such as ball skills, may be favoured by boys over girls due to the more frequent involvement of the former in such skills. Again, other skills, such as fine hand skills, favour girls, because by nature their toys, at this age, provide the opportunity for more practice. Also, for the adaptive abilities of children aged 4-8 years, according to age and gender, there is linearity in their performance (Kampas, 2003). Especially in tennis, the boys performed better in the tests that contained ball and coordination, because they had performances and experiences from their involvement with ball games, from the young age. In addition, to the above distinctions - differences between boys and girls aged 6-11 years, we had also discrimination between children, in relation to the social environment of children. Those children who had parents who were members of sports clubs differed from other children their age.

\section{REFERENCES}

Barnett, L.M., Van, Beurden, E., Morgan, P.J., Brooks L.O., \& Beard J.R. (2008). Does childhood motor skill proficiency predict adolescent fitness? Medicine Science Sports Exercise, 40(12), 2137-2144. https://doi.org/10.1249/MSS.0b013e31818160d3

Bos, K. \&Wohlmann, R. (1990).Allgemeiner sport-motorischer test fur kinder von 6 bis 11 jahren. (AST 6-11). Hanover Germany.

Doloma D. (2019).In Physical Education: Its Important Role in the Motor Development of Students. Inquiries in Sport \& Physical Education Volume 17 (1) 45 - 57 Released: March 2019.

Gallahue, D., \& Ozmun, J. (1995).Understanding Motor Development. Infants, children, adolescents, adults. USA: W.C. Brown Communications.

Hirtz, P. \&Starosta, W. (2002).Sensitive and critical periods of motor coordination development and its relation to motor learning. Journal of Human Kinetics, 7, 19-27.

Kambas, A. (2003). Coordination skills: Development and training. Thessaloniki: University Studio Press.

Kambas, A. Fatouros, I., Aggelousis, N., Gourgoulis, B. \& Taksildaris K. (2003). The effect of Age and Gender in Coordination Skills in Childhood. Research in Physical Education and Sports, 1(2), 152 158.

Magill, R., A., (1998). Motor learning: concepts and applications (5th ed). Boston, MA: McGraw-Hill.

Schmidt, R., A., \& Lee, T., D., (1999).Motor control and learning: a behavioral emphasis. Champaign IL: Human Kinetics.

Starosta, W. (2000) The importance of Movement Co-ordination, its structure and the hierarchy of integrant elements in sport and physical education. Federazione Italiana di Atletica Leggera. Motor Coordination in Sport and Exercise. Atti Convegno di Studi. University deli Study di Bologna, Faculty di Science Motorizes: Bologna.

This work is licensed under a Attribution-NonCommercial-NoDerivatives 4.0 International (CC BY-NC-ND 4.0). 